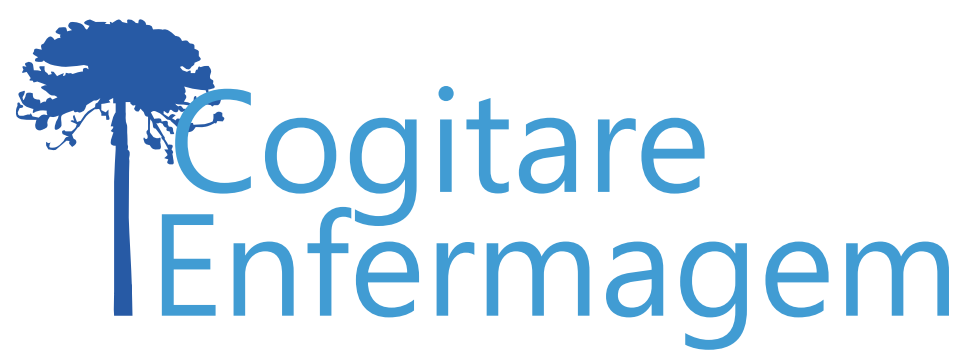

\title{
FATORES DESENCADEADORES E AMENIZADORES DA SOBRECARGA MATERNA NO AMBIENTE HOSPITALAR DURANTE INTERNAÇÃO INFANTIL
}

\author{
Amanda Marques Bezerra ${ }^{1}$ (i) \\ Fernanda Ribeiro Baptista Marques ${ }^{1}$ (1) \\ Maria Angélica Marcheti ${ }^{1}$ (1) \\ Marisa Rufino Ferreira Luizari ${ }^{1}$ (1)
}

\begin{abstract}
RESUMO
Objetivo: identificar fatores que desencadeiam e que amenizam a sobrecarga enfrentada pelas mães de crianças hospitalizadas.

Método: pesquisa exploratória descritiva de abordagem qualitativa. Os dados foram coletados de julho a agosto de 2017, com entrevista semiestruturada com sete mães acompanhantes de crianças hospitalizadas em enfermaria, em um hospital público de Campo Grande-MS. Os dados foram analisados por análise de conteúdo, gerando duas categorias analíticas: fatores que desencadeiam a sobrecarga e fatores que amenizam a sobrecarga materna.

Resultados: o cotidiano exaustivo, local de repouso inadequado e fatores emocionais como sentimentos de medo e preocupação desencadeiam sobrecarga materna. $O$ apoio familiar e dos profissionais de saúde alivia a sobrecarga das mães.

Conclusão: as mães enfrentam sobrecarga, pois centram suas forças na criança doente. Conhecer a experiência materna durante a hospitalização permite que o enfermeiro identifique suas necessidades e as inclua em seu plano de cuidado, buscando realizar intervenções para melhor assisti-la.
\end{abstract}

DESCRITORES: Enfermagem; Hospitalização; Criança; Mães; Pediatria.

\section{FACTORES DESENCADENANTES Y ATENUANTES DE LA SOBRECARGA MATERNA EN EL ENTORNO HOSPITALARIO DURANTE LA HOSPITALIZACIÓN DEL NIÑO}

\section{RESUMEN:}

Objetivo: identificar los factores que desencadenan y mitigan la sobrecarga a la que se enfrentan las madres de niños hospitalizados. Método: investigación descriptiva exploratoria con enfoque cualitativo. Los datos se recopilaron de julio a agosto de 2017, con una entrevista semiestructurada con siete madres acompañantes de niños hospitalizados en enfermería, en un hospital público de Campo Grande-MS. Los datos se analizaron mediante un análisis de contenido, generando dos categorías analíticas: factores que desencadenan la sobrecarga y factores que amenazan la sobrecarga materna. Resultados: la vida cotidiana exhaustiva, lugar de descanso inadecuado y factores emocionales como sentimientos de miedo y preocupación desencadenan sobrecarga materna. El apoyo de los familiares y de los profesionales de la salud alivia la sobrecarga de las madres. Conclusión: las madres enfrentan sobrecarga, ya que centran sus fuerzas en el niño enfermo. Conocer la experiencia de las madres durante la hospitalización permite a las enfermeras identificar sus necesidades e incluirlas en su plan de cuidados, buscando realizar intervenciones para asistirla mejor.

DESCRIPTORES: Enfermería; Hospitalización; Niño; Madres; Pediatría. 
A hospitalização infantil é um acontecimento causador de estresse e trauma para a criança, já que, junto com a internação, vem a ruptura do meio social e de suas atividades cotidianas. A criança necessita adaptar-se ao novo ambiente e sua nova rotina, sendo submetida repetidas vezes a procedimentos invasivos e dolorosos ${ }^{(1)}$. Encaram um turbilhão de sentimentos pela necessidade de separação de pessoas queridas e pelas limitações que a doença lhes impõe ${ }^{(2)}$.

As famílias são impactadas pela internação e essa experiência pode desencadear sentimentos de medo, culpa, ansiedade e impotência quanto à doença da criança. Vivenciam crises relacionadas a conflitos e desorganização familiar, e a necessidade de reorganização dos papéis. Neste momento, a família passa a ter como prioridade a saúde da criança $a^{(3)}$.

Comumente, a mãe assume a função de cuidador principal da criança, sendo elas as acompanhantes no período da internaçãa ${ }^{(4)}$. Seja por questões afetivas, legais ou morais, as mães podem deixar de lado suas necessidades pessoais em prol da recuperação do filho. Elas se deparam com alterações em sua saúde devido ao cansaço e à rotina exaustiva, o que, somadas aos medos e a falta de interesse no próprio cuidado, ocasionam a diminuição da qualidade de vida(5). As famílias desempenham papel fundamental no processo de recuperação da criança e o modo de lidarem com o estresse do momento da internação afeta a qualidade de vida de $\operatorname{ambos}^{(6)}$.

As mães são imersas no ambiente hospitalar e necessitam apreender a dinâmica do novo cenário. A depender do apoio e resiliência que têm, elas podem sentir medo, insegurança, sobrecarga e solidão(7). Quanto maior o envolvimento delas no plano terapêutico, maior a sua compreensão e concordância com o tratamento proposto. A mãe tem importante papel no processo de recuperação da criança, pois possibilita apoio, atenção e proteção ao filho(8).

É fato que as mães, por serem as que geralmente permanecem com o filho em sua hospitalização, precisam de cuidado, pois durante esse processo ficam desgastadas e temem pela desestruturação da família. Um dos elementos-chave para a atenção às famílias é o reconhecimento de sua importância e sua inclusão no cuidado e tomada de decisão(6,9).

Nesse sentido, é importante que o enfermeiro tenha uma postura aberta para a família e que estabeleça vínculo e uma relação de confiança com os familiares, para que sejam compartilhadas suas histórias e identificados pontos fortes e fracos. O compartilhamento de informações é fundamental para a elaboração de um plano de cuidados que envolva a criança e sua família. Quanto mais atenta for a escuta e a postura acolhedora do profissional, melhor será a qualidade da assistência prestada, interferindo na resposta da criança ao tratamento, no tempo de internação e no custo para a instituição.

Identificar fatores que desencadeiam ou amenizam a sobrecarga materna permite o estabelecimento de ações de acolhimento à família, fundamentadas nos pilares do Cuidado Centrado na Família: dignidade e respeito, participação, colaboração e compartilhamento de informações. Dessa forma, questionou-se o que tem desencadeado e/ou amenizado a sobrecarga materna durante a hospitalização infantil? Para responder tal questionamento, esta pesquisa foi ao campo com o objetivo de identificar os fatores que desencadeiam e os que amenizam a sobrecarga enfrentada pelas mães que acompanham crianças. 
Pesquisa exploratória descritiva de abordagem qualitativa. Utilizou-se o referencial filosófico do Cuidado Centrado no Paciente e Família.

O estudo foi realizado em uma enfermaria pediátrica de um hospital público na cidade de Campo Grande-MS. Foram incluídos familiares, com idade superior a 18 anos, que estavam acompanhando seus filhos internados há no mínimo sete dias, e foram excluídos familiares que estavam acompanhando a criança por apenas um período ou dias esporádicos.

As entrevistas foram realizadas pela pesquisadora principal, que passou por um treinamento para a aplicação do questionário e se aprofundou na temática. Os dados foram coletados nos meses de julho e agosto de 2017.

Para realizar a coleta de dados, a pesquisadora entrou em contato com a enfermeira responsável técnica e, juntas, selecionaram os participantes que se enquadravam nos critérios de inclusão; em seguida, as famílias foram convidadas individualmente para participar da pesquisa, explicando os objetivos do estudo. Após o aceite, os participantes foram conduzidos para uma sala, sem a presença e interferência de outras pessoas, e também foi apresentado a eles o Termo de Consentimento Livre e Esclarecido.

Os dados foram obtidos por meio de uma entrevista semiestruturada, em que um questionário elaborado pelas pesquisadoras foi aplicado. A primeira parte continha questões de caracterização dos participantes e a segunda questões relacionadas à sobrecarga do familiar durante a internação da criança, sendo a questão principal: Conte-me como está sendo para você a internação do (nome da criança)?

Todas as entrevistas foram gravadas em mídia digital e transcritas na íntegra pela pesquisadora, com duração média de 25 minutos. Em seguida, foi realizada leitura na integra de cada entrevista, com atenção às particularidades de cada resposta, bem como a totalidade delas, seguindo o preconizado pelo método de Análise Qualitativa de Conteúdo proposta por Morse e Field(10), baseado em análise indutiva. Após a leitura, os passos preconizados para identificação, codificação e categorização dos dados foram seguidos. A codificação linha por linha deu sequência à análise e agrupamento em subcategorias, nomeadas provisoriamente, de acordo com suas similaridades e divergências, esse momento foi realizado por duas pesquisadoras.

A fim de preservar a identidade, as participantes foram identificadas com a letra " $E$ " seguida pelo número de entrevista, por exemplo "E1".

A presente pesquisa está de acordo com os preceitos éticos da Resolução $n^{\circ} 466 / 12$ MS12(11) do Conselho Nacional de Saúde e foi aprovada no dia $1^{\circ}$ de junho de 2017 pelo Comitê de Ética em Pesquisa da Universidade Federal de Mato Grosso do Sul com o parecer $n^{\circ} 2.096 .643$.

\section{RESULTADOS}

Todas as participantes incluídas na pesquisa foram mães, que tinham em média 30 anos de idade, com variação de 20 a 53 anos. No período da coleta, não tiveram outro familiar acompanhando as crianças (como pai, avós, etc.). Dessas, quatro deixaram o trabalho para cuidar do filho doente. Das que não deixaram o trabalho: uma era autônoma, uma "do lar" e uma estava de licença médica. Das sete mães, cinco não realizavam o revezamento com outra pessoa.

Quanto ao diagnóstico médico, três crianças tinham situações crônicas de saúde (síndrome nefrótica e paralisia cerebral), as demais estavam internadas por situações 
agudas sem outras patologias associadas (leishmaniose, pneumonia, bronquiolite e septicemia). Quatro delas já haviam estado hospitalizadas anteriormente. A média de tempo de internação foi de 45 dias, sendo a menor nove dias e a maior cinco meses. Das mães entrevistadas, três residiam na cidade do estudo, uma morava em um estado vizinho e estava na cidade a passeio, as demais residiam no interior do estado.

Duas categorias emergiram das respostas das mães acompanhantes que participaram do estudo: Fatores que desencadeiam a sobrecarga das mães e Fatores que reduzem a sobrecarga das mães.

\section{Fatores que desencadeiam a sobrecarga das mães}

Dentre os fatores desencadeantes da sobrecarga relatado pelas mães, destacam-se os fatores físicos como a ambiência, necessidade de ficar em tempo integral no hospital sem revezamento, o cansaço e a vontade de estar em casa. Esses potencializaram estresse, esgotamento físico e emocional.

O local destinado para o descanso das acompanhantes é composto por uma poltrona ao lado do leito da criança. As mães relataram que as poltronas causavam dores no corpo e desencadeavam noites mal dormidas, elas sentiam-se esgotadas e atribuíram isso ao fato de as cadeiras serem velhas e pequenas.

Faz dias que estou aqui, dormindo naquela cadeira. Todo mundo está falando que estou com olheira. Eu estou esgotada! Quero dormir.... Eu não durmo direito, acordo várias vezes. (E5)

Não consigo dormir direito, a cadeira é horrível! (E1)

A permanência em tempo integral no hospital causou cansaço físico, pois não conseguiam tomar banho de forma costumeira, assim, os cuidados consigo mesmas não estavam sendo considerados satisfatórios. Permanecer em um ambiente sem atrativos e com rotinas desgastantes provocou desânimo nas mães.

...esse lugar cansativo, não dá tempo de se arrumar, não dá tempo nem de tomar banho direito. Que vontade de estar em casa! É muito cansativo. Porque a gente fica aqui parece que não tá fazendo nada, né? Mas toda hora levanta, faz isso, faz aquilo... (E2)

As mães permaneciam o tempo todo ao lado do filho por não terem com quem revezar o turno ou pela preocupação em deixar a criança sob os cuidados de outra pessoa. Outro motivo apontado foi o fato delas acreditarem que faz parte do seu papel de mãe acompanhar seu filho no período de hospitalização. Perceberam que sua permanência no hospital contribuiu para a rápida recuperação da criança.

Eu prefiro ficar aqui. Porque mesmo indo embora, eu não fico em paz, porque ia ficar pensando aqui. Entendeu? Aí eu indo embora ia ficar com a cabeça aqui. Não ia desligar, não ia descansar, não ia conseguir ficar lá... No começo minha mãe ficou aqui, mas aí ele não comeu, começou a fazer manha. Aí eu cheguei e ele mudou totalmente, começou a comer, brincar... ele necessita $100 \%$ de mim. (E1)

Tá sendo ruim ficar internada, né? Mas assim, eu tenho que ficar com ele, sou mãe dele né. Não tem ninguém que seja melhor pra ficar do que eu... é necessário que eu fique do lado dele, é meu filho, um bebezinho, é ruim ficar nessa situação de internação, mas isso é ruim pra qualquer mãe. (E3)

É uma obrigação da mãe, não temos escolha, não queríamos estar aqui, mas estamos... (E7)

A sobrecarga emocional das mães foi evidenciada quando elas manifestaram descontentamento com a autoestima. Acreditavam que não deveriam pensar em cuidar- 
se enquanto o filho estava doente. Assim, deixaram de lado os cuidados com a aparência física e higiene. Referiram que eram vaidosas e gostavam de estar arrumadas, mas se sentiam culpadas em cuidarem de sua aparência no período de hospitalização.

Diminuiu muito a autoestima, porque assim, a minha filha tá mal, eu não tenho vontade de me arrumar... E eu sou supervaidosa, é que eu sou cabeleireira e tal, no salão eu tenho que estar bem arrumada, bem vestida, maquiada. Mas aqui eu fico culpada. Assim, minha filha tá doente e eu vou ficar me arrumando? [...] Eu lavei o cabelo esses dias, fiquei um tempão sem lavar a cabeça e olha que eu cuido né. (E5)

Quando estou aqui nem penso em mim, nem na autoestima... minha autoestima é supérflua. Estou aqui pra cuidar dela [da criança]. (E7)

As mães mantiveram-se preocupadas com a situação do filho doente. Muitas vezes não dormiam para se certificarem que o filho estaria bem. Permaneciam alertas e temerosas de que algo pudessem acontecer com a criança caso dormissem.

Eu fico preocupada, esses dias ela falou que estava com dor na mãozinha, aí eu já não durmo, eu fico olhando ela de noite, vendo se está bem... Eu coloco o celular pra despertar de uma em uma hora, eu tenho medo de acontecer alguma coisa e eu não ver. (E5)

A preocupação com os demais filhos, que ficaram em casa, também permeou as experiências das mães na hospitalização. Entendiam que a criança internada requeria a sua permanência no hospital, mas estar longe dos demais filhos as faziam pensar que eles também necessitavam de cuidados e sentiam saudades.

É ruim por causa da minha outra filha, sinto mais falta dela. Porque ela tá assim, entre a casa da minha mãe e a casa do meu ex-marido... a outra faltou aula, porque o pai dela mora longe da escola, ficou uma semana sem estudar. (E5)

Só não está bom porque estou longe dos meus outros filhos. Mas tá bom na medida do possível né?... penso o tempo todo neles. (E1)

Elas se abalavam, pois sentiam que não podiam fazer nada pela situação do filho adoecido e, quando acontecia algo que demandava algum cuidado específico com ele, se desesperavam e não sabiam como lidar ou como ajudar.

Quando ele foi embora fazer a diálise peritoneal, a máquina apitava, ele chorava, eu chorava junto, não sabia o que fazer! Aquele desespero! (E6)

\section{Fatores que reduzem a sobrecarga das mães}

Durante os relatos, foi possível identificar fatores que diminuíam a sobrecarga materna. Entre eles, o apoio familiar foi considerado de grande importância pelas mães participantes, especialmente quando os membros familiares ajudavam com os afazeres domésticos e com os cuidados com os filhos que ficaram em casa. Além disso, o revezamento entre os membros ajudou no descanso das mães, permitiu que elas saíssem por alguns momentos do ambiente hospitalar, realizassem afazeres domésticos e revessem os outros filhos.

Então me ajuda né [o revezamento], sei que lá tá bem e aqui também tá bem, porque meu marido a única diferença entre eu e ele ficar com meu filho é que ele mama e eu tenho o peito né? [risos], mas é a única diferença, meu marido pode suprir muita coisa. (E3)

Me ajuda bastante [o revezamento] pela questão do descanso, pra mim ir em casa dormir e também que eu posso fazer alguma coisa lá, lavar roupa, trazer alguma coisa que está precisando, ver meu outro filho, ajudar ele em alguma coisa, que ele sempre tá precisando. Porque ele é pequeno. (E3)

O apoio dos profissionais de enfermagem auxiliou as mães a se sentirem confiantes 
na tarefa de cuidado do filho. Referiram que tiveram alguém a quem recorrer quando acontecia algo que elas não possuíam conhecimento para solucionar.

Não, é cansativo, mas difícil não. Difícil não porque as enfermeiras ajudam, né? Tem todo o apoio das enfermeiras. (E2)

A experiência de permanecer com o filho no hospital possibilitou às mães reflexão e aprendizagem quanto a lidar com os desafios da vida e com a doença da criança. Perceberam que se fortaleciam mais a partir da experiência de estar com a criança no hospital.

No começo eu fiquei preocupada [com a criança], nossa eu quase morri! Falei com Deus, porque sou evangélica, ia ali à capela, agora estou bem graças a Deus, vejo diferente, me sinto mais forte. (E5)

...ele [a criança] me dá força a cada minuto, a cada hora, cada dia. Então, ele me fortalece, eu aprendo com isso. (E1)

Com a hospitalização da criança, as mães passaram a valorizar a ajuda de pessoas externas à família e a ver as situações difíceis vividas por um outro prisma.

Eu aprendi muita coisa aqui que eu não valorizava antigamente, né? Tipo, eu era orgulhosa, não queria ajuda de ninguém. Hoje em dia eu preciso da ajuda de um monte de gente. É difícil, mas a gente tem que aprender a deixar o orgulho de lado e viver.... Melhorou minha autoestima. Aprendi muitas coisas que achei que não era importante na minha vida e hoje em dia sei que é, vejo por outro ângulo. (E1)

O apoio dos membros da equipe de saúde configurou-se como fator importante para o sentimento de bem-estar e alívio da sobrecarga emocional das mães acompanhantes. $O$ vínculo entre a família e a equipe tornou a experiência das mães mais leve e positiva.

Eu me sinto bem aqui dentro, aqui eu me sinto como se eu tivesse na minha família também, porque o amor que eu tenho aqui dentro é muito grande por todo mundo, sabe? As meninas [equipe de enfermagem] mesmo é como se fosse minha família. (E4)

\section{DISCUSSÃO}

Os resultados deste estudo apontam situações desencadeadoras de sobrecarga materna, especialmente por ser a mãe a principal cuidadora no período de hospitalização e por não compartilhar o cuidado do filho com outros membros da família. O hospital revelase um ambiente desconfortável, não oferecendo condições para que elas descansem, cuidem de si próprias ou distraiam-se. Por outro lado, a abordagem acolhedora da equipe de enfermagem torna a estadia dessas mães no hospital mais tranquila.

As participantes desse estudo possuíam características semelhantes às de outros, que também encontraram a predominância de mães que acompanhavam as crianças ${ }^{(12)}$ com média de 30 anos de idade e que muitas vezes necessitam deixar seus empregos para se dedicar ao cuidado da criança e acompanhá-las no tratamento(13-14).

Os espaços físicos e acomodações inadequadas do hospital para o devido descanso das mães acompanhantes e a permanência ininterrupta com a criança ocasionaram cansaço e desânimo. Tal dado foi evidenciado em pesquisa ${ }^{(15)}$ realizada em uma enfermaria pediátrica, que buscou descrever as necessidades do acompanhante da criança hospitalizada durante sua permanência na enfermaria; destacou-se a insatisfação das mães acerca da sua condição de permanência na enfermaria pelas condições estruturais, por não terem onde lavar e secar suas roupas e por não terem banheiro exclusivo, entre outros aspectos. 
Diante disso, torna-se necessária a reorganização dos espaços das enfermarias pediátricas, de modo a permitir a permanência do acompanhante que garanta a qualidade do sono, descanso e bem-estar.

Durante a internação da criança, as acompanhantes vivenciam situações que prejudicam sua saúde física, como a falta de sono e repouso causada principalmente por não possuírem um local adequado para o descanso. Estudos ${ }^{(16-17)}$ apontam a importância do sono e repouso, afetados pelo desconforto proporcionado pelas poltronas dos hospitais. Evidencia-se a relevância do preparo hospitalar para a recepção e permanência das famílias, a fim de acolhê-las adequadamente.

Estudos ${ }^{(17-18)}$ discorrem sobre os sentimentos negativos de medo e insegurança que permeiam o período de hospitalização e adoecimento da criança, trazendo à tona a importância do enfermeiro para a amenização destes sentimentos. Por permanecer por mais tempo na enfermaria, o enfermeiro tem a possibilidade de se aproximar da família, buscando esclarecer suas dúvidas e aliviar a angústia que a experiência de adoecimento e hospitalização gera.

A baixa autoestima das mães acompanhantes também foi destacada, pois não se sentem motivadas e não encontram condições para isso. Ações devem ser propostas para que elas sejam encorajadas a dedicarem tempo para o autocuidado durante a sua permanência com o filho no hospital. As condições oferecidas pelo hospital também afetam diretamente na alimentação, na higiene pessoal e no autocuidado dessas mães. Quando o sono e o repouso são afetados, as mães apresentam tristeza, impotência e medo frente à internação(16). Mudanças nas normas e rotinas da unidade e uma assistência qualificada dos profissionais podem ajudar as mães a passar pelos desafios para os quais nem sempre se sentem preparadas.

Neste estudo, três das crianças internadas possuíam doenças crônicas, demandando maior tempo e dedicação das mães e representando maior impacto na família. O contexto da doença crônica implica em hospitalizações frequentes e aumento na sobrecarga e estresse de todos os membros familiares. Esse contexto requer um acompanhamento mais direto dos enfermeiros e demais profissionais de saúde.

Evidencia-se a necessidade de espaço apropriado para as acompanhantes permanecerem com seus filhos no ambiente hospitalar e para serem ouvidas suas dúvidas e anseios. Outros autores ${ }^{(15-16,19)}$ apontam a necessidade do profissional de saúde possuir olhar holístico, incluindo as necessidades dos acompanhantes que permanecem internados com a criança, proporcionando maior bem-estar e um ambiente seguro.

O revezamento com outros membros da família é essencial para as mães, reduz a sobrecarga delas no período de internação da criança e alivia o estresse. A rede de apoio familiar é de grande importância neste contexto, pois frequentemente há a necessidade de redefinição de papéis dentro da família. As mães que permanecem com a criança no hospital precisam se sentir seguras quanto à continuidade da rotina de casa e do cuidado com os demais filhos, e devem ser encorajadas a contatar sua rede de apoio para auxiliar nas atividades.

Apesar das consequências negativas que a hospitalização infantil ocasionou nas mães, é possível identificar uma aprendizagem adquirida. O apoio da família, dos amigos e da equipe de saúde auxilia na potencialização da ressignificação do momento que estão vivendo, tornando a experiência menos traumática ${ }^{(20)}$. Tais fatores que minimizam a sobrecarga devem ser otimizados, por meio de rodas de conversa que permitam a troca de experiência entre mães que vivenciam situações semelhantes, e da utilização de tais espaços para solução de dúvidas e compreensão da visão individual de cada acompanhante.

Nesse sentido, o Institute for Patient-and Family-Centered Care propõe às instituições de saúde um modelo assistencial em que a família é incluída em todo o plano de cuidado, e propõe a incorporação de quatro pressupostos centrais: dignidade 
e respeito, compartilhamento de informação, participação, e colaboração. Esses pilares precisam estar incorporados no serviço em todas as esferas (administrativas, de apoio e assistenciais), a fim de que a família se perceba cuidada e atendida em suas necessidades. Ademais, propõe uma estrutura arquitetônica moldada nesses modelo de cuidado(21).

Como limitações deste estudo, têm-se a inclusão de apenas um hospital público para coleta dos dados e o fato de ter incluído as mães de crianças com doenças crônicas, que possuem experiência de internações longas e recorrentes. A fragilidade emocional aparente das mães nas entrevistas também pode configurar uma limitação. Sugere-se que futuras investigações sejam realizadas em outras realidades, a fim de identificar diferenças e semelhanças da realidade vivenciada em outras instituições.

\section{CONSIDERAÇÕES FINAIS}

A pesquisa demonstrou que as mães das crianças hospitalizadas enfrentam situações que podem desencadear sobrecarga física e emocional. A baixa autoestima das acompanhantes foi evidenciada e traz consigo o sentimento de culpa, uma vez que o filho requer a total dedicação delas no período de hospitalização. Outro fator que contribui para a baixa autoestima é a não disponibilidade de um espaço que garanta a privacidade e o conforto da mãe para sua higiene e cuidados pessoais.

Não ter um local apropriado de descanso, a dificuldade no revezamento nos cuidados da criança, o isolamento dos demais membros da família e os sentimentos de tristeza, medo e preocupação com a criança doente ou com os outros filhos que permanecem em casa, desencadeiam sobrecarga física e emocional na mãe acompanhante.

Em contraponto, encontram no apoio familiar, na equipe de enfermagem e na própria criança doente a força e a motivação que precisam para prosseguirem. Sentiremse apoiadas minimiza a sobrecarga emocional e o sofrimento experienciado no contexto, favorecendo vínculos de confiança entre elas e a equipe.

Assim, torna-se necessário que o enfermeiro inclua as mães em seu processo de cuidado, criando oportunidades para que sejam ouvidas. Os hospitais necessitam favorecer o espaço para momentos de conversas terapêuticas, a fim de ouvir suas dúvidas e anseios. Além disso, precisam desenvolver meios de oferecer melhores condições para a permanência das mães acompanhantes e incluí-las no processo de cuidado do filho.

\section{REFERÊNCIAS}

1. Santos PM dos, Silva LF da, Depianti JRB, Cursino EG, Ribeiro CA. Nursing care through the perception of hospitalized children. Rev bras. enferm. [Internet]. 2016 [acesso em 13 nov 2017]; 69(4). Disponível em: http://dx.doi.org/10.1590/0034-7167.2016690405i.

2. Bezerra JC, Oliveira LCB de, Maia EMC. Estresse e qualidade de vida em crianças com doenças renais crônicas hospitalizadas. Psic., Saúde \& Doenças. [Internet]. 2016 [acesso em 22 abr 2020]; 17(3). Disponível em: http://dx.doi.org/10.15309/16psd170306.

3. Ferreira LB, Oliveira JSA de, Gonçalves RG, Elias TMN, Medeiros SM de, Mororó DD de S. Cuidar de enfermagem às famílias de crianças e adolescentes hospitalizados. Rev. enferm. UFPE on line. [Internet]. 2019 [acesso em 22 abr 2020]; 13(1). Disponível em: https://pesquisa.bvsalud.org/portal/resource/pt/ biblio-1005939. 
4. Bham SQ, Saeed F, Shah MA. Knowledge, Attitude and Practice of mothers on acute respiratory infection in children under five years. Pak J Med Sci. [Internet]. 2016 [acesso em 29 mar 2019]; 32(6). Disponível em: https://doi.org/10.12669/pjms.326.10788.

5. Pavão TL, Montalvão TC de. Mães acompanhantes de crianças cardiopatas: repercussões emocionais durante a hospitalização. Revista Psicologia e Saúde. [Internet]. 2016 [acesso em 01 abr 2019]; 8(2). Disponível em: http://pepsic.bvsalud.org/pdf/rpsaude/v8n2/v8n2a06.pdf.

6. Curtis K, Foster K, Mitchell R, ConnieVan. Models of Care Delivery for Families of Critically III Children: An Integrative Review of International Literature. J Ped Nurs [Internet]. 2016 [acesso em 01 abr 2019]; 31(3). Disponível em: https://doi.org/10.1016/j.pedn.2015.11.009.

7. Lima RM, Gomes FMA, Aguiar FAR, Santos Junior EB dos, Dourado JVL, Ferreira Junior AR. Experiências de mães durante a internação hospitalar de seus filhos. J. res. fundam. care online. [Internet]. 2019 [acesso em 31 mar 2020]; 11(5). Disponível em: http://www.seer.unirio.br/index.php/ cuidadofundamental/article/viewFile/7510/pdf 1.

8. Vieira RFC, Souza TV de, Oliveira IC dos S, Morais R de CM de, Macedo IF de, Gois JR de. Mães/ acompanhantes de crianças com câncer: apreensão da cultura hospitalar. Esc Anna Nery [Internet]. 2017 [acesso em $01 \mathrm{abr} 20]$; 21(1). Disponível em: http://www.scielo.br/pdf/ean/v21n1/1414-8145-ean-2101-e20170019.pdf.

9. Azevêdo AV dos S, Lançoni Junior AC, Crepaldi MA. Nursing team, family and hospitalized child interaction: an integrative review. Ciênc. saúde coletiva [Internet]. 2017 [acesso em 01 abr 2019]; 22(11). Disponível em: http://dx.doi.org/10.1590/1413-812320172211.26362015.

10. Teixeira MA, Nitschke RG, Paiva MS. Análise dos dados em pesquisa qualitativa: um olhar para a proposta de Morse e Field. Rev. Rene. [Internet]. 2008 [acesso em 02 abr 20]; 9(3). Disponível em: http:// www.periodicos.ufc.br/rene/article/view/5083/3723.

11. Ministério da Saúde (BR). Conselho Nacional de Saúde. Diretrizes e normas regulamentadoras de pesquisa envolvendo seres humanos. Resolução n. 466, de 12 de dezembro de 2012. Brasília; 2012.

12. Velhote $A B$, Bohomol E, Velhote MCP. Reações do acompanhante diante dos procedimentos préoperatórios em cirurgia pediátrica ambulatorial. Einstein. [Internet] 2016 [acesso em 30 out 2020]; 14(3). Disponível em: https://doi.org/10.1590/S1679-45082016A03624.

13. Melo D da S, Frizzo GB. Depressão, ansiedade e suporte familiar para mães na primeira hospitalização dos filhos. Psicologia, Saúde \& Doenças. [Internet]. 2017 [acesso em 30 out 2020]; 18(3). Disponível em: http://dx.doi.org/10.15309/17psd180315.

14. Lima RM, Gomes FMA, Aguiar FAR, Santos Júnior EB dos, Dourado JVL, Ferreira Junior AR. Experiências de mães durante a internação hospitalar de seus filhos. J. res. fundam. care online [Internet]. 2019 [acesso em 30 out 2020]; 11(5). Disponível em: http://dx.doi.org/10.9789/2175-5361.2019. v11i5.1286-1292.

15. Morais R de CM de, Souza TV de, Oliveira IC dos S. A (in)satisfação dos acompanhantes acerca de sua condição de permanência na enfermaria pediátrica. Esc Anna Nery [Internet]. 2015 [acesso em $01 \mathrm{abr}$ 2019]; 19(3). Disponível em: http://dx.doi.org/10.5935/1414-8145.20150053.

16. Strasburg A da C, Pintanel AC, Gomes GC, Mota MS. Cuidado de enfermagem a crianças hospitalizadas: percepção de mães acompanhantes. Rev Enferm UERJ. [Internet] 2011 [acesso em 22 abr 2020]; 19(2). Disponível em: http://repositorio.furg.br/handle/1/1545.

17. Joaquim RHVT, Barbano LM, Bombarda TB. Necessidades das famílias em enfermaria pediátrica: a percepção dos próprios atores. Rev. ter. ocup. [Internet]. 2017 [acesso em 01 abr 2019]; 28(2). Disponível em: https://doi.org/10.11606/issn.2238-6149.v28i2p181-189.

18. Vieira RFC, Souza TV de, Oliveira IC dos S, Morais R de CM de, Macedo IF de, Gois JR de. Mães/ acompanhantes de crianças com câncer: apreensão da cultura hospitalar. Esc Anna Nery [Internet]. 2017 [acesso em 30 out 2020]; 21(1). Disponível em: https://www.scielo.br/scielo.php?pid=S1414- 
19. Neves FG, Moraes JRMM de, Morais R de CM, Souza TV de, Ciuffo LL, Oliveira IC dos S. O trabalho da enfermagem em emergência pediátrica na perspectiva dos acompanhantes. Esc Anna Nery. [Internet]. 2016 [acesso em 01 abr 2019]; 20(3). Disponível em: http://dx.doi.org/10.5935/1414-8145.20160063.

20. Barros SMM de, Monteiro PAL, Neves MB, Maciel GT de S. Fortalecendo a rede de apoio de mães no contexto da Síndrome Congênita do vírus Zika: relatos de uma intervenção psicossocial e sistêmica. Nova perspect. sist. [Internet]. 2017. [acesso em 02 nov 2020]; 58. Disponível em: https://revistanps.com.br/ nps/article/view/296/282.

21. Institute for Patient- and Family- Centered Care. Advancing the practice of patient- and familycentered care in hospitals: How to Get Started. IPFCC. [Internet]. 2017 [acesso em 12 fev 2021].

Disponível em: https://www.ipfcc.org/resources/getting started.pdf.

\section{COMO REFERENCIAR ESTE ARTIGO:}

Bezerra AM, Marques FRB, Marcheti MA, Luizari MRF. Fatores desencadeadores e amenizadores da sobrecarga materna no ambiente hospitalar durante internação infantil. Cogitare enferm. [Internet]. 2021 [acesso em "colocar data de acesso, dia, mês abreviado e ano"]; 26. Disponível em: http://dx.doi.org/10.5380/ce.v26i0.72634.

Recebido em: 07/04/2020

Aprovado em: 10/12/2020

Editora associada: Tatiane Herreira Trigueiro

Autor Correspondente:

Amanda Marques Bezerra

Universidade Federal de Mato Grosso do Sul - Campo Grande, MS, Brasil

E-mail: amandamarquesb@outlook.com

Contribuição dos autores:

Contribuições substanciais para a concepção ou desenho do estudo; ou a aquisição, análise ou interpretação de dados do estudo - AMB, FRBM

Elaboração e revisão crítica do conteúdo intelectual do estudo - AMB, FRBM, MAM, MRFL

Aprovação da versão final do estudo a ser publicado - MAM

Copyright (C) 2021 Este é um artigo em acesso aberto distribuído nos termos da Licença Creative Commons Atribuição, que permite o uso irrestrito, a distribuição e reprodução em qualquer meio desde que o artigo original seja devidamente citado. 